\title{
Concentrations of MMP-9 and TIMP-1 in lip tissue and their impact on cleft lip surgery healing
}

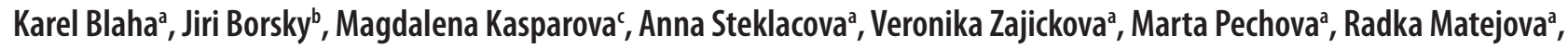 \\ Karel Kotaska', Tatjana Dostalovac
}

Aim. To compare aspects of wound healing after cleft lip surgery performed within one week of age and wound healing after surgery performed within 2 - 4 months of age, especially concentrations of matrix metalloproteinase-9 (MMP-9) and tissue inhibitor of metalloproteinases-1 (TIMP-1) in tissue removed during surgery.

Methods. 34 tissue samples ( 26 boys and 8 girls) were removed during surgery within one week of age $(n=19)$ or within 2 - 4 months of age $(n=15)$. Tissue samples were separated into epidermis, dermis and mucous membrane. Proteins were extracted in cacodylic buffer for $24 \mathrm{~h}$ at a temperature $2-8^{\circ} \mathrm{C}$. Total protein concentrations were examined using a modification of the Lowry method. Samples were examined using ELISA kit Amersham Biotrak Activity Assay (GE Healthcare UK) for detection of MMP-9 and TIMP-1 concentrations.

Results. MMP-9: early surgery - epidermis $2.168 \pm 3.303 \mu \mathrm{g} / \mathrm{g}$ of protein (mean $\pm \mathrm{SD}$ ), dermis $1.251 \pm 1.848 \mu \mathrm{g} / \mathrm{g}, 2$ - 4 months surgery - epidermis $0.347 \pm 0.212 \mu \mathrm{g} / \mathrm{g}$, dermis $0.555 \pm 0.276 \mu \mathrm{g} / \mathrm{g}$. TIMP-1: early surgery - epidermis $1.762 \pm 2.162$ $\mu \mathrm{g} / \mathrm{g}$, dermis $1.628 \pm 0.822 \mu \mathrm{g} / \mathrm{g}$, mucous membrane $2.066 \pm 1.717 \mu \mathrm{g} / \mathrm{g}, 2$ - 4 months surgery - epidermis $1.881 \pm 2.810$ $\mu \mathrm{g} / \mathrm{g}$, dermis $3.117 \pm 1.540 \mu \mathrm{g} / \mathrm{g}$, mucous membrane $4.833 \pm 6.550 \mu \mathrm{g} / \mathrm{g}$.

Conclusions. There were no significant differences in concentrations of protein MMP-9 in epidermis and dermis and TIMP-1 in epidermis and mucous membrane according to time of surgery. Significantly decreased levels of TIMP-1 in dermis were found in samples obtained from early surgery compared to levels in samples obtained from 2 - 4 months surgery.

Key words: matrix metalloproteinases, cleft lip, wound healing

Received: December 13, 2011; Accepted: August 27, 2012; Available online: October 31, 2012

http://dx.doi.org/10.5507/bp.2012.088

${ }^{a}$ Department of Clinical Biochemistry and Pathobiochemistry, $2^{\text {nd }}$ Faculty of Medicine, Charles University in Prague and Faculty Hospital Motol, Prague, Czech Republic

${ }^{b}$ Department of Plastic Surgery, Faculty Hospital Kralovske Vinohrady, Prague

'Department of Paediatric Stomatology, $2^{\text {nd }}$ Faculty of Medicine, Charles University in Prague and Faculty Hospital Motol, Prague

Corresponding author: Karel Blaha, e-mail: Blaha.Karel@fnmotol.cz

\section{INTRODUCTION}

Cleft lip is one of most common congenital malformations in humans. Labioplasty performed on infants to repair such defects often results in severe scar formation ${ }^{1}$.

Wounds in fetuses heal rapidly and generally without scar formation until late gestation. Adult skin wounds heal by scar formation, while fetal skin wounds heal without scar formation by a process resembling regeneration rather than repair ${ }^{2}$. Relative to that in adults, fetal wound repair is characterized by more epithelization, fibroblast migration, extracellular matrix (ECM) deposition, and ultimate restoration of normal tissue architecture ${ }^{3}$. In early gestation, the amount and organization of ECM may be associated with scarless repair of fetal skin wounds ${ }^{2}$. The amount and organization of normal wound ECM are determined by a dynamic balance among overall matrix synthesis, deposition, and degradation ${ }^{4}$.

The composition and organization of ECM are governed by matrix metalloproteinases ${ }^{2}$. Matrix metalloproteinases (MMPs) play major roles in tissue regeneration and remodeling 5 . MMPs comprise a group of structur- ally related enzymes that are collectively able to cleave practically all types of ECM molecules and various other substrates including other proteases, growth factors and cytokines $^{6}$. MMP-9 (92 kDa gelatinase) protein expression has been reported in the epidermal cells of acute wounds ${ }^{5}$. MMP-9 catalyzes cleavage of denatured collagens of all types and native basement membrane components ${ }^{7}$.

MMP activity is further controlled by a group of protein inhibitors called tissue inhibitors of metalloproteinases (TIMPs) $\left(\right.$ ref. $^{8}$ ). Four TIMPs (TIMP-1, TIMP-2, TIMP-3, and TIMP-4) have been identified in vertebrates, and their expression is regulated during development and tissue remodeling ${ }^{9}$. All TIMPs can inhibit all the MMPs, but with different levels of potency, whereas TIMP-1 preferentially inhibits MMP-9 $\left(\right.$ ref. $\left.^{2}\right)$.

We hypothesized that MMP-9 or TIMP-1 may have a role in scarless healing after cleft lip surgery. We compared levels of MMP-9 and TIMP-1 in tissue removed during surgery performed within one week where children were healing with reduced scarring with levels in tissue removed during surgery performed within 2 - 4 months where healing was by scar formation. 


\section{MATERIAL AND METHODS}

34 tissue samples ( 26 boys and 8 girls) were obtained from children suffering from cleft lip. The patients were divided into two groups according to the time of the surgery. Surgery was performed during early gestation period - within one week of age $(n=19)$ or during later gestation period - within 2 - 4 months of age $(n=15)$. Assays were performed in samples of excessive tissue removed during surgery. After collection, samples were stored at $-70^{\circ} \mathrm{C}$ until assays were performed. Tissue samples were separated to epidermis, dermis and mucous membrane. MMP9 was not investigated in mucous membrane. Separation was performed mechanically using scissors under microscope. Samples were placed in cacodylic buffer (cacodylic acid $\mathrm{C}_{2} \mathrm{H}_{7} \mathrm{AsO}_{2} 10 \mathrm{mmol} / \mathrm{L}, \mathrm{NaCl} 0.15 \mathrm{~mol} / \mathrm{L}, \mathrm{CaCl}_{2} 20$ $\mathrm{mmol} / \mathrm{L}, \mathrm{ZnCl}_{2} 0.001 \mathrm{mmol} / \mathrm{L}, \mathrm{NaN}_{3} 1.5 \mathrm{mmol} / \mathrm{L}$ and $0.01 \%$ Triton X-100), and then homogenized. Proteins were extracted in cacodylic buffer for $24 \mathrm{~h}$ in temperature $2-8^{\circ} \mathrm{C}$. We used a volume of four times sample weight. After extraction, the supernatant was separated by centrifugation (30 min at $13000 \mathrm{G})$.

MMP-9 and TIMP-1 concentrations were adjusted to total protein concentrations. Total protein concentrations were examined using a modification of the Lowry method $\left(\mathrm{Na}_{2} \mathrm{CO}_{3} 0.19 \mathrm{~mol} / \mathrm{L}, \mathrm{NaOH} 0.1 \mathrm{~mol} / \mathrm{L}, \mathrm{CuSO}_{4}\right.$ $0.125 \mathrm{~mol} / \mathrm{L}, \mathrm{C}_{4} \mathrm{H}_{4} \mathrm{KNaO}_{6} 0.095 \mathrm{~mol} / \mathrm{L}$, Folin reagent $\left(\mathrm{Na}_{2} \mathrm{WO}_{4}, \mathrm{Na}_{2} \mathrm{MoO}_{4}, \mathrm{H}_{3} \mathrm{PO}_{3}, \mathrm{HCl}, \mathrm{Li}_{2} \mathrm{SO}_{4}, \mathrm{Br}\right)$, working range $0.01-1 \mathrm{mg} / \mathrm{L}$, wavelength $750 \mathrm{~nm}$ ). The method was validated at concentration levels of $0.040 \mathrm{mg} / \mathrm{mL}$ (Coefficient of variation $-\mathrm{CV}_{1}=13.43 \%$ ) and $0.085 \mathrm{mg} /$ $\mathrm{mL}\left(\mathrm{CV}_{2}=18.25 \%\right)$.

Samples were examined using ELISA kit Amersham Biotrak Activity Assay (GE Healthcare UK) for detection of MMP-9 and TIMP-1 concentrations.

\section{Statistical analysis}

Unpaired tests (Mann-Whitney) were used to compare MMP-9 (epidermis, dermis) and TIMP-1 (epidermis and mucous membrane) concentrations. Unpaired t-tests were used to compare TIMP-1 concentrations in dermis. Value of $P<0.05$ was assumed significant. For analysis, the software GraphPad 5.03 (San Diego, California) was used.

\section{RESULTS}

Table 1. shows concentration of MMP-9 isolated from the lip tissue related to the age of children in the time of surgery. (Results expressed as mean $\pm \mathrm{SD}$ ).

Fig 1. shows data presented as boxes (mean, 2.5 and 97.5 percentiles) and whisker (higher and lower values) plots. Differences between groups are expressed as $P=0.200$ in epidermis and $P=0.866$ in dermis.

Table 2. shows concentration of TIMP-1 isolated from the lip tissue related to the age of children in the time of surgery. (Results expressed as mean $\pm \mathrm{SD}$ ).
Table 1. Concentration of MMP-9 isolated from the lip tissue related to the age of children in the time of surgery.

\begin{tabular}{lcc}
\hline & $\begin{array}{c}\text { Epidermis } \\
(\mu \mathrm{g} / \mathrm{g} \text { of total protein })\end{array}$ & $\begin{array}{c}\text { Dermis } \\
(\mu \mathrm{g} / \mathrm{g} \text { of total protein })\end{array}$ \\
\hline 1 week & $2.168 \pm 3.303$ & $1.251 \pm 1.848$ \\
$2-4$ months & $0.347 \pm 0.212$ & $0.555 \pm 0.276$ \\
\hline
\end{tabular}

Results are expressed as mean \pm SD.

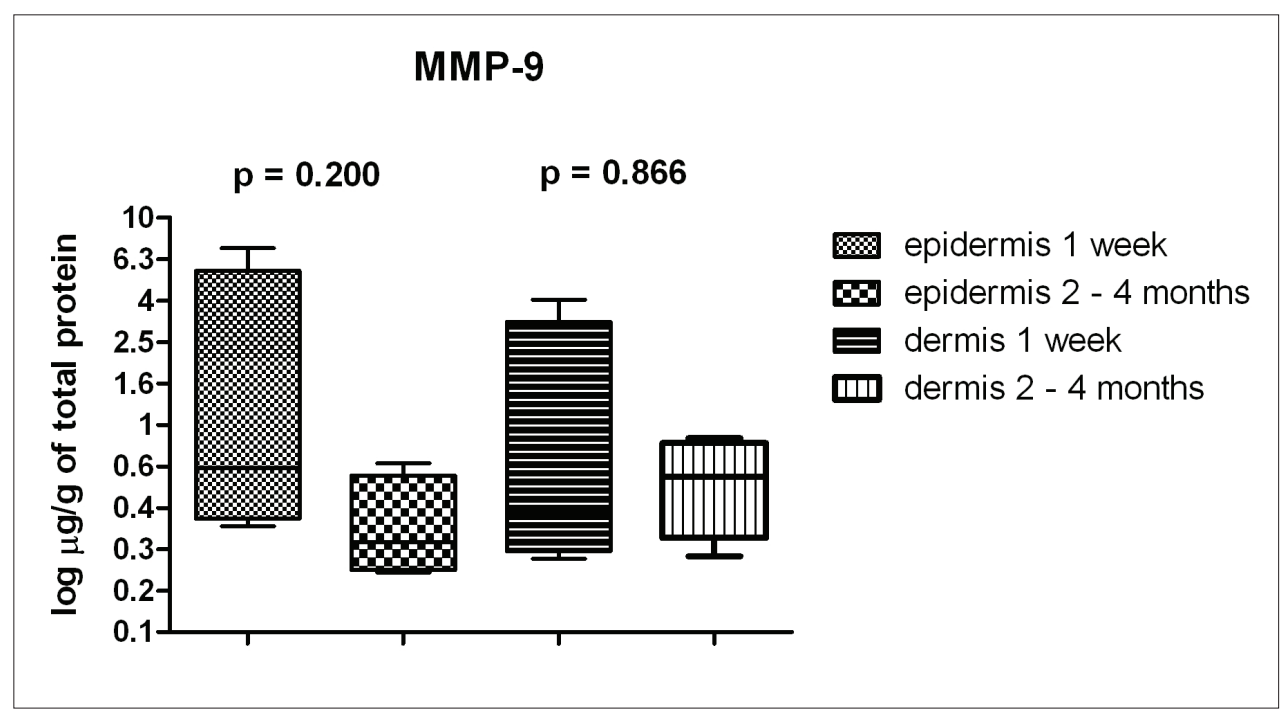

Fig. 1. Data presented as boxes (mean, 2.5 and 97.5 percentiles) and whisker (higher and lower values) plots. Differences between groups are expressed as $P=0.200$ in epidermis and $P=0.866$ in dermis. 
Table 2. Concentration of TIMP-1 isolated from the lip tissue related to the age of children in the time of surgery.

\begin{tabular}{lccc}
\hline & $\begin{array}{c}\text { Epidermis } \\
(\mu \mathrm{g} / \mathrm{g} \text { of total protein })\end{array}$ & $\begin{array}{c}\text { Dermis } \\
(\mu \mathrm{g} / \mathrm{g} \text { of total protein })\end{array}$ & $\begin{array}{c}\text { Mucous membrane } \\
(\mu \mathrm{g} / \mathrm{g} \text { of total protein })\end{array}$ \\
\hline 1 week & $1.762 \pm 2.162$ & $1.628 \pm 0.822$ & $2.066 \pm 1.717$ \\
$2-4$ months & $1.881 \pm 2.810$ & $3.117 \pm 1.540$ & $4.833 \pm 6.550$ \\
\hline
\end{tabular}

Results are expressed as mean $\pm \mathrm{SD}$.

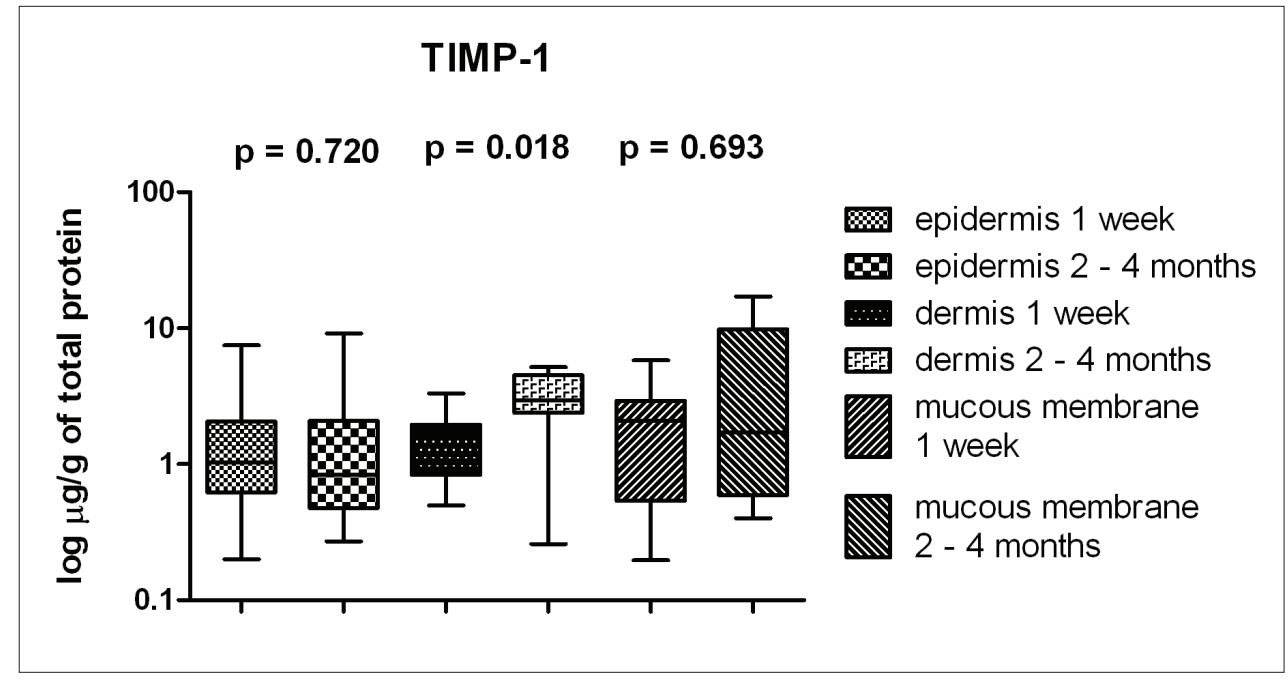

Fig. 2. Data expressed as boxes (mean, 2.5 and 97.5 percentiles) and whisker (higher and lower values) plots. Differences between groups are expressed as $P=0.720$ in epidermis, $P=0.018$ in dermis and $P=0.693$ in mucous membrane.
Fig 2. shows data expressed as boxes (mean, 2.5 and 97.5 percentiles) and whisker (higher and lower values) plots. Differences between groups are expressed as $P=0.720$ in epidermis, $P=0.018$ in dermis and $P=0.693$ in mucous membrane.

\section{DISCUSSION}

The cleft defect severely deforms the face aesthetically, significantly complicates food intake, breathing and unoperated defects may negatively affect the development of speech. Intellect is mostly unaffected. The technique of cleft repair and surgical skills play a very important role in obtaining good results, but we assume there are other aspects which could influence aesthetics and healing after the surgery. Of these, timing of the operation plays an important role $\mathrm{e}^{10}$.

According to traditional treatment protocols, surgical cleft lip repair is performed at the age 3 - 4 months. Surgical repair of the cleft lip at a standard age of 3 months often results in severe residual scar formation. Cleft lip repair performed as soon after the birth as possible according to the general health of the patient is believed to be beneficial especially in scarless healing. Scars on the upper lip in patients treated shortly after the birth are visibly more aesthetic ${ }^{10}$.

Studies of the role of MMPs and TIMPs in scarless healing have been described in mice, human fetuses and adult humans. No previous studies of the role of MMP-9 and TIMP-1 in scarless healing after cleft lip surgery on human neonates have been published.
The purpose of this study was to compare the aspects of wound healing after cleft lip surgery performed within one week of age and wound healing after surgery performed within 2 - 4 months of age. The main aim was to examine ECM involved in wound healing, especially concentrations of MMP-9 and TIMP-1 in tissue removed during surgery. While MMP-9 and TIMP-1 play a role in healing, we hypothesized that levels of MMP-9 and TIMP1 could be different in the two groups.

Our results show that levels of MMP-9 were increased in samples received from early surgery compare to samples received from 2 - 4 months surgery (epidermis, dermis), but the differences were not significant $(P=0.200$, $P=0.866$ ). This fact is caused by small group of samples and nonparametric data distribution resulting in SDs overlapping means as is shown in table 1.

Scars after surgical repair of the cleft lip in neonates are composed of heavily deposited type I collagen fibers ${ }^{1}$. MMPs are required for regular skin wound healing and the distinctive pattern of their expression has been implicated in promoting scarless healing. The family of collagens is a major component of the wound extracellular matrix and the major substrate for MMPs action ${ }^{11}$. Type I collagen can be remodeled by several MMPs including MMP-9 (ref. ${ }^{1}$ ).

High expression of MMP-9 during the skin repair process was described on mice models ${ }^{11,12}$. These studies show that high expression of MMP-9 during skin repair process lead to scarless healing. Similar results were found in our group of children where healing without scar formation correlated with high levels of MMP-9. High levels of MMP-9 expressions can at least partially explain collagen 
turnover (production vs degradation) and different kinetics of wound reorganization ${ }^{11,12}$. According to Hosokawa MMP-9 expression and activity implicates the promotion of type I collagen degradation at the site of surgery. MMP9 activity is low or undetectable in hypertrophic scars where collagen is excessive ${ }^{1}$.

Fetal wounds are characterized by highly organized collagen deposition ${ }^{3}$. Chen investigated the expression profiles of MMP-9 and TIMP-1 in human fetal and adult skins in order to examine the hypothesis that these enzymes are involved in skin development and wound healing, as well as the possible mechanism regulating fetal scarless healing. According to this study endogenous MMP-9, and endogenous inhibitors might be involved in skin development and in maintenance of cutaneous structure and function. Lower protein content of TIMP-1 in early gestational skin might provide a predominantly antiscarring signal while higher protein expression of this inhibitor might be associated with scar-forming healing in late gestational and adult skins ${ }^{2}$.

This finding correlates with results of our study. Our results show, that levels of TIMP-1 in dermis were significantly lower in samples from early surgery compare to samples from 2 - 4 months surgery $(P=0.018)$. Levels of TIMP-1 were decreased in samples received from early surgery compare to samples received from 2 - 4 months surgery (epidermis, mucous membrane) but the differences were not significant $(P=0.720, P=0.693)$.

\section{CONCLUSION}

While concentrations of MMP-9 were increased in tissue samples removed during surgery performed within 1 week, no significant differences in concentrations of protein MMP-9 between the two groups according to the time of the surgery were found. Lower levels of TIMP-1 in dermis in samples received from early surgery compared to levels in samples received from 2 - 4 months surgery were found. No significant differences in concentration of TIMP-1 in epidermis and mucous membrane according to time of surgery were found. Investigation of TIMP concentrations in tissue samples at different times of cleft lip surgery seems to be promising in wound healing.

\section{ABBREVIATIONS}

CV; Coefficient of variation, ECM; Extracellular matrix, MMP; Matrix metalloproteinase, SD; Standard deviation, TIMP; Tissue inhibitor of metalloproteinases

\section{ACKNOWLEDGEMENT}

This work was supported by IGA MZCR NS/10012-4 and 00064203 (FN Motol).

\section{CONFLICT OF INTEREST STATEMENT}

Author's conflict of interest disclosure: None declared.

\section{REFERENCES}

1. Hosokawa R, Nonaka K, Morifuji M, Shum L, Orishi M. TGF- $\beta 3$ decreases type I collagen and scarring after labioplasty. Journal of Dental Research 2003;82:7.

2. Chen W, Fu X, Ge S, Sun T, Sheng Z. Differential expression of matrix metalloproteinases and tissue-derived inhibitors of metalloproteinase in fetal and adult skins. Int J Biochem Cell Biol 2007;39(5):9971005.

3. Lorenz HP, Adzick NS. Scarless skin wound repair in fetus. Fetal Medicine [Special Issue]. West J Med 1993;159:350-5.

4. Soo C, Shaw WW, Zhang X, Longaker MT, Howard EW, Ting K. Differential expression of matrix metalloproteinases and their tissuederived inhibitors in cutaneous wound repair. Plast Reconstr Surg 2000;105(2):638-47.

5. Dasu MR, Spies M, Barrow RE, Herndon DN. Matrix metalloproteinases and their tissue inhibitors in severely burned children. Wound Repair Regen 2003;11(3):177-80.

6. Toriseva M, Kahari V.M. Proteinases in cutaneous wound healing Cell Mol Life Sci 2009; 66(2):203-24.

7. Mohan R, Chintala SK, Jung JC, Villar WV, McCabe F, Russo LA, Lee Y, McCarthy BE, Wollenberg KR, Jester JV, Wang M, Welgus HG, Shipley JM, Senior RM, Fini ME. Matrix metalloproteinase gelatinase B (MMP9) coordinates and effects epithelial regeneration. J Biol Chem 2002;277(3):2065-72

8. Reed MW, Buttle D, Cross SS, Brown NJ. Matrix metalloproteinase activity and immunohistochemical profile of matrix metalloproteinase- 2 and -9 and tissue inhibitor of metalloproteinase- 1 during human dermal wound healing. Wound Repair Regen 2004; 12(3):295-304.

9. Visse R, Nagase H. Matrix metalloproteinases and tissue inhibitors of metalloproteinases. structure, function, and biochemistry. Circ Res 2003;92(8):827-39.

10. Ziak P, Fedeles J Jr, Fekiacova D, Hulin I Jr, Fedeles J. Timing of primary lip repair in cleft patients according to surgical treatment protocol. Bratisl Lek Listy 2010;111(3):160-2.

11. Gawronska-Kozak B. Scarless skin wound healing in FOXN1 deficient (nude) mice is associated with distinctive matrix metalloproteinase expression. Matrix Biol 2011;30(4):290-300.

12. Manuel JA, Gawronska-Kozak B. Matrix metalloproteinase 9 (MMP-9) is upregulated during scarless wound healing in athymic nude mice. Matrix Biol 2006;25(8):505-14. 